\title{
Enrolment \& Dropout Percentage among Boys \& Girls up to Secondary Level in India: A Comparative Study
}

\author{
Ramesh Pandita* \\ BGSB University, Rajouri, Jammu \& Kashmir, R/o 274-C, Durga Nagar Sect. No I, P/o Roop Nagar, \\ Jammu - 180013, India \\ *E-mail address: rameshpandita90@gmail.com
}

\begin{abstract}
Purpose: The present paper seeks to examine the enrolment and dropout percentage of children in India, supported with empirical findings up to secondary level. Although, the study is general in nature, but the emphasis has been laid on the girl child education, which is one of the greatest concerns in the Indian school education sector. Some of the aspects studied include, enrolment and dropout of children during the period of study, under both boys and girls category, their corresponding growth rate in enrolment, their corresponding decline rate in dropout and many other allied aspects.

Scope: The study is confined to secondary level education and the findings have direct bearing on the Indian school education system. Given the population size of India and the socioeconomic conditions of the country, there is a need to observe caution, while generalizing the findings for other countries.

Methodology/Approach: The present study is purely based on the analysis of secondary data retrieved from the official website of the Ministry of Human Resource and Development, Govt., of India. The data lasts for the decade 2001-02 to 2010-11 and was retrieved on October 02, 2014. Since the data on the website stands up-dated up to the year 2010-11, as such the findings simply reflect a trend in the enrolment and dropout percentage in India and may show variation by the time figures are updated.

Findings: The study reveals that during the period of study, the enrolment percentage of girls has improved over two fold to that of boys. As, compared to $18.17 \%$ increase in the overall enrolment of boys, the enrolment percentage of girls increased by $40.52 \%$ during the decade. The corresponding growth surely reflects the changed mindset of male dominated Indian social setup towards the girl child. Even, the average annual dropout percentage of girls remained better to that of boys, as the girls recorded a corresponding decline in their dropout percentage by $3.53 \%$, while as in case of boys the dropout percentage declined by $2.54 \%$ annually. Despite all these positives, the discouraging part is that compared to $57.39 \%$ boys, $60.39 \%$ girls' dropout by or before reaching the upper primary level and against $78.40 \%$ boys, $81.72 \%$ girls' dropout by or before reaching the secondary level.

Social Implications: Given the new and changed world order, no country can afford to remain elusive of basic formal education, what is commonly known as elementary education and so holds true of India. The study is a positive indicator of the growing awareness among Indian masses towards the promotion of girl child education, but still there is lot yet to be done to reduce the dropout percentage between upper primary and secondary level for both boys in general and girls in particular.
\end{abstract}

Keywords: Education; School Education; Primary; Upper Primary; Secondary; Enrolment; Dropout 


\section{INTRODUCTION}

The problem of children dropout is not confined to one or two countries of the world, but is a global problem; even the developed nations of the world do suffer on this account. Hammack (1986), Mann (1986), \& Canadian Manpower and Immigration (1990) in their respective studies have observed that high school dropout is one of the biggest problems, as more than one third of the high school children in US and Canada dropout, without receiving high school diplomas. Surely, the problem is more severe in developing and under-developing countries of the world. Still more, the problem of child dropout varies considerably from country to country and region to region for different reasons and varied factors. As per the Global Education Digest (GED) 2012 Report, out of every 10 children enrolled, 4 dropout in Sub-Saharan Africa, 3 in West and South Asia and 2 in the Latin America \& the Caribbean, the same report also highlights that nearly 32 million primary pupil repeat in a grade and $80 \%$ of them are from these three regions of the world. On average, 9\% children repeat in SubSaharan Africa, 8\% in Latin America and Caribbean and 5\% in West and South Asia.

As per the 2011 population census of Govt. of India, India is a home of more than 1.21 billion people in the world, the second most populous country in the world after China. What is more interesting about the population of India is, India is rated as a young country, for the fact that more than $65 \%$ population of the country is below 35 years of age and more than $13 \%$ population of the country is in the age group of 0-6 years. The Literacy rate of India as per 2011 census is $74.04 \%$, which has improved by $9.21 \%$ since the 2001 , when the literacy rate of India was $65.46 \%$. Given the population size of India and its socio-economic status, the problem of child dropout is somewhat endemic in India's social setup.

In the present study attempt has been made to work out the dropout percentage of children enrolled in schools in India up to secondary level, during the last decade, viz., for the period 2001-02 to 2010-11. The study also covers the aspects like overall enrolment and dropout percentage of children in India, irrespective of any caste or category with emphasis on girl child. Every care has been taken to project the comparative empirical findings about the enrolment and dropout of both boys and girls separately.

\section{REVIEW OF LITERATURE}

Educationists all over the world have undertaken a good number of studies to assess and examine the reasons which primarily contribute to the school dropout among children. Some of the studies undertaken earlier have been reviewed hereunder to develop better understanding of the subject and the problem, so that present study may be guided on the acceptable lines for better readership and clearer empirical findings.

As per the Quebec Ministry of Education report (1991), in the whole of Canada and entire Quebec province, of the total dropouts $40 \%$ were girl students, however vellerand, Fortier \& Guay (1993) in their study discussed about the self-determination among women. The authors found that compared to men who have a more motivational profile in life activities be it sports, leisure, interpersonal relationship or education. Vallerand and Bissonnette (1992) in their study found that compared to $16 \%$ men only $9 \%$ women in college courses dropout.

Rumberger and Larson (1998) in their study concerning to increased risk of high school dropout in US and found that the student mobility reduces the odds of high school graduation and found that students, who change their school even ones between the eighth and twelfth 
grades were less likely to complete high school. Cairns, Cairns \& Neckerman (1989), while studying the detriments of child dropout, analysed 248 girl students and 227 boys. The authors observed that, $14 \%$ of the students dropped out before completing their high school. The authors also observed that, $82 \%$ dropout among boys and $47 \%$ among girls in grade seven dropped out either by high levels of aggression or low levels of academic performance. The added factors, which authors found do contribute to the dropout ratio include, socioeconomic status, race and early parenthood.

Sabha \& Gauri (2012) while studying causal factors in Indian suburbs of Uttar Pradesh found that, compared to $33.89 \%$ boys, $16.56 \%$ girls dropped out for personal reasons, $20.34 \%$ boys \& $47.02 \%$ girls owed their dropout to familial factors, $8.47 \%$ boys \& $5.29 \%$ girls have blamed school as reason for their dropout and compared to $37.29 \%$ boys $\& 31.13 \%$ girls have shifted the dropout responsibility to their socio-economic conditions. Mondal \& Majumder (2013) in a similar study undertaken in West Bengal, associated the dropout problem of children in rural India with their socio-economic conditions. The authors are of the view that dropout percentage between boys and girls vary considerably and the social \& economic factors are primarily responsible for dropouts up to primary level along with other factors like parental occupation etc.

Sara et al. (2000) in their study, while assessing the dropout rate among high school students conducted and compared the test of five theories and found that poor academic achievement has a direct and major bearing on the dropout ratio of children and the general deviance, bonding with non-conformist peers, and socioeconomic status contributes equally in this regard. Dreze \& Kingdon (1999) in their study conducted on the north Indian rural children on school dropouts studied different variables, which contributed to their dropout percentage. Some of the aspects studied by the authors include parental education, motivation, social background, village development, teacher postings, teacher regularity and midday meals. The authors observed that parent-teacher coordination plays a very significant role in the grade attainments and the mid-meal on the other hand has improved the chances of completing the primary education among girls by $30 \%$ than those areas where mind-day meal scheme is not available. Similarly, children of educated parents will dropout, is very unlikely.

Hymel et al (1996) in their study concerning school dropout, has put emphasis over the four different aspects of peer influence, which together contribute to the dropout of a child, these include, prior social acceptance and rejection, social isolation vs involvement, the negative influence of peers and the aggression and antisocial behaviour. Pittman \& Haughwout (1987) in their study conducted in US, while analyzing the data collected from 744 public schools found that, size of the school acts as a detriment, which influences the dropout of children. The authors are of the view, that school consolidation and social climate is given little attention, which they attributed as a factor likely to increase the chances of early school dropout.

Fetler (1989) while correlating school dropouts to academic performance, size and poverty, questioned the policy makers for setting higher academic standards. The author is of the view that school effectiveness measures, which can result into higher academic performance, helps in proving effective in dropout programmes. Josheph (2014) in his study conducted in West Bengal developed a Positive Psycho-Education Intervention (PPRI) programme to overcome the depressive symptoms among children, which leads to their dropout. The author conducted study on 68 dropout boys selected randomly from suburbs and found that the programme proved effective in enhancing engagement, motivation and alleviation among students in overcoming depressive symptoms of dropout. 


\section{OBJECTIVES OF THE STUDY}

To understand and examine the overall enrolment and dropout ratio of school going children up to the secondary level for all categories of students, including those belonging to socially disadvantaged sections of Indian society.

To draw comparisons between the boys and the girls in their enrolment and dropout percentage, with special emphasis on the girl child.

\section{SCOPE \& METHODOLOGY}

At the first stage, the scope of the present study is totally confined to the union of India, which at the second stage has got further delimited to school education in India and at the third stage study stands confined up to dropout percentage of children enrolled up to secondary level in India during the period 2001-02 to 2010-11.

The present study has been undertaken on the secondary data retrieved from the official website of the Ministry of Human Resource \& Development, Govt., of India, on October 02, 2014, accessible at http://mhrd.gov.in/statist?field_statistics_category_tid=33. The data upon retrieval was in semi structured form, as such was first structured as per the objectives of the study. The data has been presented in the tabulated form in most convenient and easy to understand way, so that readers may not find it difficult to have clear, broader and better grasping of the problem under study. Data has also been systematically tabulated in a form, whereby it becomes easier to study and understand the defined objectives. To perform the computations like addition, subtraction, division and drawing percentage, etc., simple mathematical tools and techniques have been employed in the data analysis.

\section{LIMITATIONS OF THE STUDY}

By and large the present study is free from any major limitation, but it is pertinent to mention here that the data retrieved from the official website of the Ministry of Human Resource \& Development, Govt., of India for school education stands up dated up to the year 2010-11, hence the findings of the present study may simply reflect the trend of enrolment and dropout in school education in India. There is every likeliness that findings may vary with updated data for any period.

\section{DATA ANALYSIS}

The data has been tabulated separately for both the boys \& the girls, so as to workout enrolment and dropout ratio under both the categories. Accordingly, the data has been tabulated for scheduled castes and scheduled tribes, the two main under privileged sections of Indian socioeconomic setup. Percentage at most of the places has drawn up to two decimal places as such may reflect slight variation when the figures are computed for 100 percent.

Annual corresponding growth and annual corresponding decline percentage has been computed by using following formula. 
CG- Corresponding Growth, CD-Corresponding Decline

$$
\begin{aligned}
& \text { End Value - First Value } \\
& C G=\text {-------------------- } \times 100 \\
& C D=\text { End Value }- \text { First Value }
\end{aligned}
$$

\begin{tabular}{|c|c|c|c|c|c|c|c|c|c|c|}
\hline \multirow{2}{*}{ Year } & \multicolumn{4}{|c|}{$\begin{array}{c}\text { Enrolment Figures in Millions of } \\
\text { Classes }\end{array}$} & \multirow{2}{*}{$\begin{array}{c}\text { CG } \\
\%\end{array}$} & \multicolumn{4}{|c|}{$\begin{array}{c}\text { Dropout Percentage Figures of } \\
\text { Classes }\end{array}$} & \multirow{2}{*}{$\begin{array}{l}\text { CD } \\
\%\end{array}$} \\
\hline & I-V & $\begin{array}{l}\text { VI- } \\
\text { VIII }\end{array}$ & IX-X & Total & & I-V & $\begin{array}{c}\text { VI- } \\
\text { VIII }\end{array}$ & IX-X & Total & \\
\hline 2001-02 & 113.90 & 44.80 & 20.10 & 178.80 & - & 39.0 & 54.6 & 66.0 & 53.20 & - \\
\hline 2002-03 & 122.40 & 46.90 & 21.80 & 191.10 & 6.87 & 34.9 & 52.8 & 62.6 & 50.10 & -5.82 \\
\hline 2003-04 & 128.30 & 48.80 & 23.30 & 200.40 & 4.86 & 31.5 & 52.3 & 62.7 & 48.83 & -2.53 \\
\hline 2004-05 & 130.80 & 51.20 & 24.30 & 206.30 & 2.94 & 29.0 & 50.8 & 61.9 & 47.23 & -3.27 \\
\hline $2005-06$ & 132.10 & 52.20 & 25.00 & 209.30 & 1.45 & 25.7 & 48.8 & 61.6 & 45.36 & -3.95 \\
\hline 2006-07 & 133.70 & 54.50 & 25.90 & 214.10 & 2.29 & 25.6 & 45.9 & 59.9 & 43.80 & -3.43 \\
\hline 2007-08 & 135.50 & 57.30 & 28.20 & 221.00 & 3.22 & 25.1 & 42.7 & 56.7 & 41.50 & -5.25 \\
\hline 2008-09 & 135.30 & 58.40 & 29.40 & 223.10 & 0.95 & 27.8 & 39.3 & 54.2 & 40.43 & -2.57 \\
\hline 2009-10 & 133.60 & 59.50 & 30.70 & 223.80 & 0.31 & 30.3 & 42.5 & 52.7 & 41.83 & 3.46 \\
\hline 2010-11 & 134.80 & 61.90 & 31.90 & 228.60 & 2.14 & 27.4 & 40.8 & 49.2 & 39.13 & -6.45 \\
\hline Avg & 130.00 & 53.55 & 26.06 & 209.65 & 2.50 & 29.63 & 47.05 & 58.75 & 45.13 & -2.98 \\
\hline
\end{tabular}

Table 1. Enrolment \& dropout figures of all school children in India during the period (2001-02 to 2010-11).

CG\%-Corresponding Growth Percentage CD\%-Corresponding Decline Percentage

The gross enrolment for all classes during the decade has increased by $27.85 \%$, while as during the same period the enrolment up to primary level has increased by $18.34 \%$, for upper primary level by $38.16 \%$ and for secondary level $58.70 \%$. On the other hand the worrying aspect is, that nearly $58.80 \%$ students' dropout by the time they reach upper primary level and $79.95 \%$ dropout by the time they reach secondary level. Accordingly, on year to year basis a constant and continuous corresponding growth has been observed in the enrolment of children which on average has grown at $2.50 \%$ annually. 


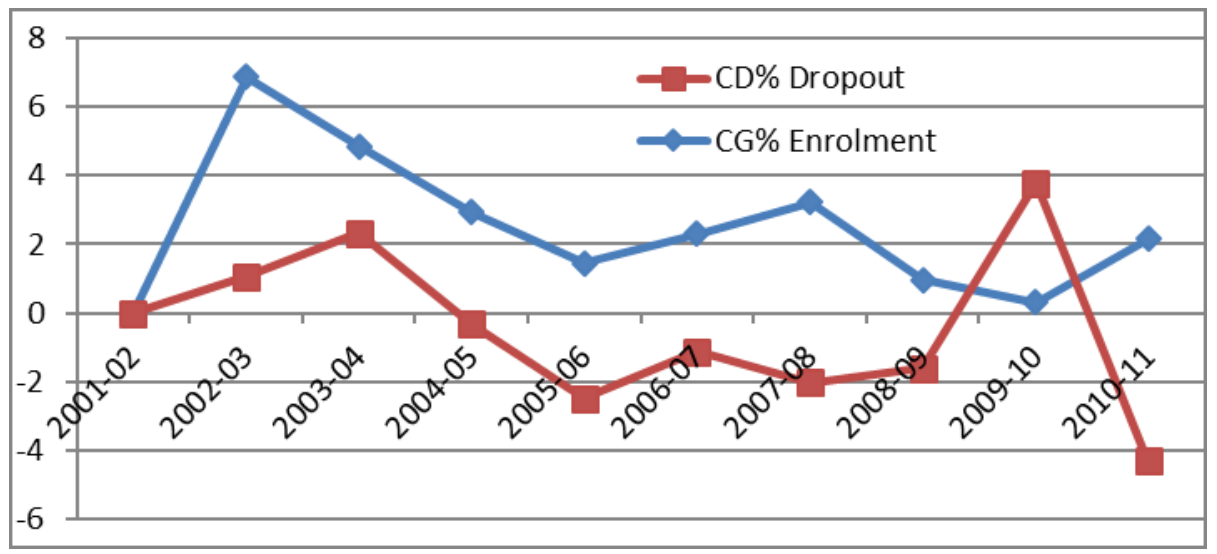

Figure 1. (Frequency Curves of Corresponding Growth in Enrolment and Corresponding Decline percentage in Dropout for all children).

It is equally noteworthy, that there has been a constant decline in the dropout percentage of children during the each corresponding year. Except for the year 2009-10, the decline in dropout was recorded during each year with an average dropout decline of $2.98 \%$ annually. The average annual dropout percentage during the period of study for primary level remained $29.63 \%$, for upper primary level $47.05 \%$ and for secondary level, $58.75 \%$, while as, the overall average annual dropout for all classes during the period remained $45.13 \%$.

Table 2. Enrolment \& dropout figures of all school children (Boys) in India during the period (200102 to $2010-11)$.

\begin{tabular}{|c|c|c|c|c|c|c|c|c|c|c|}
\hline \multirow{2}{*}{ Year } & \multicolumn{4}{|c|}{$\begin{array}{l}\text { Enrolment Figures in Millions } \\
\text { of Classes }\end{array}$} & \multirow{2}{*}{ CG\% } & \multicolumn{4}{|c|}{$\begin{array}{c}\text { Dropout Percentage Figures of } \\
\text { Classes }\end{array}$} & \multirow{2}{*}{ CD\% } \\
\hline & I-V & $\begin{array}{l}\text { VI- } \\
\text { VIII }\end{array}$ & IX-X & Total & & I-V & I-VIII & I-X & Avg & \\
\hline 2001-02 & 63.60 & 26.10 & 12.10 & 101.80 & - & 38.4 & 52.9 & 64.2 & 51.83 & - \\
\hline 2002-03 & 65.10 & 26.30 & 12.80 & 104.20 & 2.35 & 35.9 & 52.3 & 60.7 & 49.63 & -4.24 \\
\hline 2003-04 & 68.40 & 27.30 & 13.70 & 109.40 & 4.99 & 33.7 & 51.9 & 61.0 & 48.86 & -1.55 \\
\hline 2004-05 & 69.70 & 28.50 & 14.20 & 112.40 & 2.74 & 31.8 & 50.5 & 60.4 & 47.56 & -2.66 \\
\hline $2005-06$ & 70.50 & 28.90 & 14.50 & 113.90 & 1.33 & 28.7 & 48.7 & 60.1 & 45.83 & -3.63 \\
\hline 2006-07 & 71.10 & 29.90 & 14.90 & 115.90 & 1.75 & 24.6 & 46.4 & 58.6 & 43.20 & $\begin{array}{l}-5.73 \\
\end{array}$ \\
\hline $2007-08$ & 71.10 & 31.10 & 15.90 & 118.10 & 1.89 & 25.7 & 43.7 & 56.6 & 42.00 & -2.77 \\
\hline 2008-09 & 70.60 & 31.40 & 16.50 & 118.50 & 0.33 & 29.6 & 41.1 & 54.0 & 41.56 & -1.04 \\
\hline 2009-10 & 69.70 & 31.70 & 16.90 & 118.30 & -0.16 & 31.8 & 41.1 & 53.3 & 42.06 & 1.20 \\
\hline $2010-11$ & 70.10 & 32.70 & 17.50 & 120.30 & 1.69 & 29.0 & 40.6 & 50.2 & 39.93 & -5.06 \\
\hline Avg & 68.99 & 29.39 & 14.90 & 113.28 & 1.69 & 30.92 & 46.92 & 57.91 & 45.24 & -2.54 \\
\hline
\end{tabular}

CG\%-Corresponding Growth Percentage CD\%-Corresponding Decline Percentage

Given the varying enrolment and dropout scenario of boys and girls, it is imperative to have a clear idea and analyze some fundamental differences between the children of opposite gender. The overall enrolment percentage of boys in Indian schools during the period of study has increased by $18.17 \%$, which up to primary level increased by $10.22 \%$, for upper primary level $25.28 \%$ and for secondary level by $44.62 \%$. A constant and continuous growth was recorded in the overall enrolment of boys during the period of study, except for the year 200910 , when the enrolment percentage dropped by $0.16 \%$ from the corresponding year. However 
the average annual enrolment growth recorded during the period remained $1.69 \%$. It is equally interesting to note that $57.39 \%$ male student's dropout without qualifying upper primary level and $78.40 \%$ dropout without obtaining secondary level diplomas.

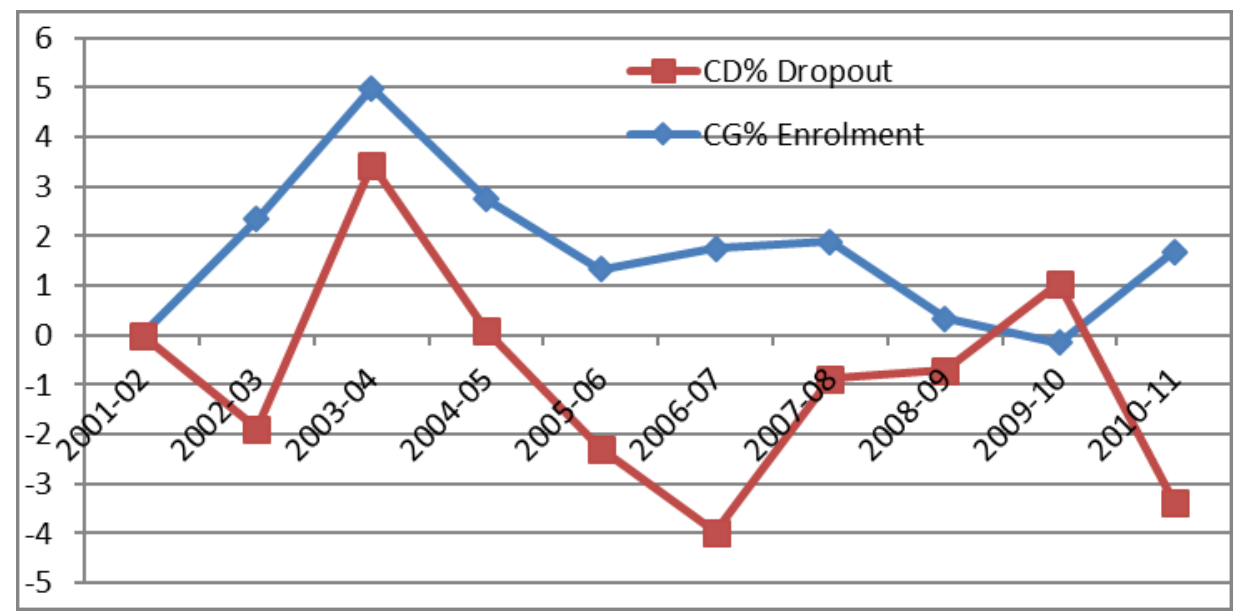

Figure 2. (Frequency Curves of Corresponding Growth in Enrolment and Corresponding Decline percentage in Dropout for Boys).

The average annual dropout percentage recorded for all male children during the period of study remained $45.24 \%$, while as for the same period the dropout percentage recorded up to primary level among boys remained $30.92 \%$, for upper primary level $46.92 \%$ and for secondary level 57.91\%. A constant and continuous decline was observed in the dropout percentage of the male students, except during the year 2009-10, when it decreased by $1.20 \%$ from the corresponding year. The average corresponding dropout percentage among boys declined by $2.54 \%$ annually.

Table 3. Enrolment \& dropout figures of all school children (Girls) in India during the period (2001-02 to 2010-11).

\begin{tabular}{|c|c|c|c|c|c|c|c|c|c|c|}
\hline \multirow{2}{*}{ Year } & \multicolumn{3}{|c|}{$\begin{array}{c}\text { Enrolment Figures in } \\
\text { Millions of Classes }\end{array}$} & \multirow{2}{*}{ Total } & \multirow{2}{*}{ CG\% } & \multicolumn{2}{|c|}{$\begin{array}{c}\text { Dropout Percentage } \\
\text { Figures of Classes }\end{array}$} & \multirow{2}{*}{ Avg } & \multirow{2}{*}{ CD\% } \\
\cline { 2 - 7 } & I-V & $\begin{array}{c}\text { VI- } \\
\text { VIII }\end{array}$ & IX-X & & & I-V & $\begin{array}{c}\text { I- } \\
\text { VIII }\end{array}$ & I-X & & \\
\hline $\mathbf{2 0 0 1 - 0 2}$ & 50.30 & 18.70 & 7.90 & 76.90 & - & 39.9 & 56.9 & 68.6 & 55.13 & - \\
\hline $\mathbf{2 0 0 2 - 0 3}$ & 57.30 & 20.60 & 9.00 & 86.90 & 13.00 & 33.7 & 53.5 & 65.0 & 50.73 & -7.98 \\
\hline $\mathbf{2 0 0 3 - 0 4}$ & 59.90 & 21.50 & 9.60 & 91.00 & 4.71 & 28.6 & 52.9 & 64.9 & 48.80 & -3.80 \\
\hline $\mathbf{2 0 0 4 - 0 5}$ & 61.10 & 22.70 & 10.10 & 93.90 & 3.18 & 25.4 & 51.3 & 63.9 & 46.86 & -3.97 \\
\hline $\mathbf{2 0 0 5 - 0 6}$ & 61.60 & 23.30 & 10.50 & 95.40 & 1.59 & 21.8 & 49.0 & 63.6 & 44.80 & -4.39 \\
\hline $\mathbf{2 0 0 6 - 0 7}$ & 62.60 & 24.60 & 11.00 & 98.20 & 2.93 & 26.8 & 45.2 & 61.5 & 44.50 & -0.66 \\
\hline $\mathbf{2 0 0 7 - 0 8}$ & 64.40 & 26.20 & 12.30 & 102.90 & 4.78 & 24.4 & 41.3 & 57.3 & 41.00 & -7.86 \\
\hline $\mathbf{2 0 0 8 - 0 9}$ & 64.70 & 27.00 & 13.00 & 104.70 & 1.74 & 25.8 & 36.9 & 54.4 & 39.03 & -4.80 \\
\hline $\mathbf{2 0 0 9 - 1 0}$ & 63.90 & 27.80 & 13.80 & 105.50 & 0.76 & 28.5 & 44.2 & 51.8 & 41.50 & 6.32 \\
\hline $\mathbf{2 0 1 0 - 1 1}$ & 64.60 & 29.20 & 14.30 & 108.10 & 2.46 & 25.4 & 41.2 & 47.7 & 38.10 & -8.19 \\
\hline Avg & 61.01 & 24.16 & 11.15 & 96.35 & 3.51 & 28.03 & 47.24 & 59.87 & 45.04 & -3.53 \\
\hline
\end{tabular}

CG\%-Corresponding Growth Percentage CD\%-Corresponding Decline Percentage 
During the period of study, the gross enrolment percentage of girl students in India have increased by $40.52 \%$, which is more than twofold higher than the enrolment growth recorded for the boys during the same period. Up to primary level, the overall enrolment percentage during the decade has increased by $28.42 \%$, for upper primary level by $56.14 \%$ and for secondary level by $81.01 \%$. The annual corresponding growth of the female students during the period has also increased steadily, with an average annual corresponding growth of $3.51 \%$. It is equally notable that, by the time these girl students reach primary level nearly $60.39 \%$ drop out and by the time they reach secondary level $81.72 \%$ girl students dropout.

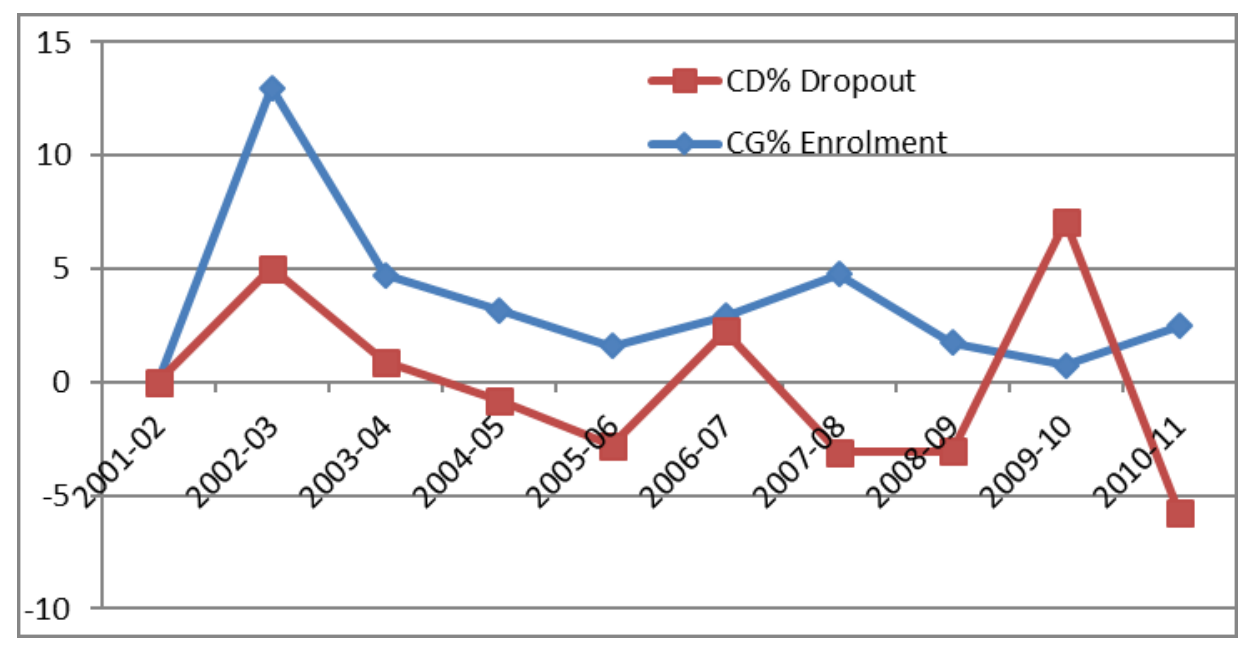

Figure 3. Frequency Curves of Corresponding Growth in Enrolment and Corresponding Decline percentage in Dropout for all Girls.

The aggregate average annual dropout percentage for girl students during the period remained $45.04 \%$, while as, up to primary level the dropout percentage remained $28.03 \%$, for upper primary level $47.24 \%$ and for secondary level $59.87 \%$. Although there has been a consistent and constant decline in the dropout percentage of girl students from each corresponding year, but for the period 2009-10, the dropout percentage decreased by $6.23 \%$. The overall corresponding annual dropout percentage among girl students during the period of the study remained $3.53 \%$, which is quite appreciable, compared to their male counterparts.

\section{SUMMARY OF FINDINGS \& DISCUSSION}

The problem of child dropout is deep rooted in Indian school education system and despite some laudable measures taken by both the state and the central governments; the problem of enrolment and dropout has not been addressed to that extent to which it should have been. The problem of child dropout percentage increases with each higher class and this apart from various other reasons is influenced by the practice of repeating a class. Children most of the time get discouraged when they are asked to repeat a particular class with the result they tend to dropout.

Compared to boys, whose enrolment percentage during the period of study increased by $18.17 \%$, the enrolment percentage of girls increased by $40.52 \%$, which is over twice that of the boys. This exponential growth in the girl child enrolment percentage during the last decade speaks volumes about the shift in the male mindset towards girl child education. 
Indian girl child, who otherwise hitherto used to receive step motherly treatment in most of the social endeavours, including education can be expected of ushering in a new dawn in their social standing and education of girl child will play a key part in every other sphere of their activity, they will venture into.

The dropout percentage of $45.04 \%$ among girls is considerably better to that of boys who during the same period dropped out by $45.24 \%$. Similarly, the overall average corresponding growth in enrolment among boys remained $1.69 \%$, while as for girls it remained $3.51 \%$ annually. This again is an indicator of the fact that education of the girl child is being taken seriously by their parents. So, on the whole there is a paradigm shift in the promotion of girl child education in India and people are actively responding to the concerns raised by various agencies, thinkers, NGO's, \& Individuals from time to time.

The average dropout percentage among boys declined by $2.54 \%$, while as among girls dropout percentage declined by $3.53 \%$ annually, which also means that the dropout percentage of girls remained $38.97 \%$ lesser to that of boys. This is an indication of the fact that dropout chances among girls is far lesser than the boys, provided the conditioning supports. Even one cannot rule out the angle of greater interest among girls towards education than the boys, since hypothetical, hence leaves enough scope for further studies in this direction.

Despite so many positives in the improvement of girl child education, the discouraging aspect is that compared to $57.39 \%$ boys, $60.39 \%$ girls' dropout by the time they reach an upper primary level and against $78.40 \%$ boys, $81.72 \%$ girls' dropout by the time they reach secondary level. Early marriage or child marriage, looking after their young siblings and supporting mothers as domestic help are being seen as the prime reasons for the early dropout percentage among girls, but surely demands for further studies in this area.

From the data analysis, it is quite evident, that a girl child has started receiving treatment at par with boys and is no more deprive from fundamental education. Although, there has been a considerable improvement in the enrolment and dropout percentage of girl child, but at the same time this enthusiasm needs to be carried forward with additional support and there should be no letup in this regard.

There is equally need to understand that literacy rate of a country cannot be a measure of its educational strength and outreach, as these are mere figures and not the applied aspect of real education. Higher the levels of formal educational attainments better are the chances that same attainments will get reflected and transferred into practice. So there is greater need to take education far beyond the levels of mere achieving the ability of reading and writing.

\section{SOME GOVERNAMENTAL MEASURES}

It is equally important to mention, that the various schemes launched by govt., of India from time to time towards the promotion of education have helped a great deal in increasing the enrolment percentage of children in schools, especially of the girl child and so holds true about the decline in their dropout percentage. Mid Day Meal Scheme is one of the largest \& widely acknowledged one, which has proved advantageous in many ways? Parents have started believing that apart from providing free education, their wards are being provided with free staple food, which has reduced the burden from parents to support the teaching of their wards and provision of wholesome diet necessary for the growth, development and health of their wards. 
Table 4. Some of the centrally sponsored schemes launched in the education sector by the Ministry of Human Resource Development, Govt., of India include.

\begin{tabular}{|c|c|}
\hline S.No & Name of the Scheme \\
\hline 01 & Sarva Shiksha Abhiyan (SSA) \\
\hline 02 & Kasturba Gandhi Balika Vidyalaya \\
\hline 03 & National Programme for Education of Girls at Elementary Level (NPEGEL) \\
\hline 04 & Mid Day Meal Scheme (MDMS) \\
\hline 05 & Mahila Samakhya \\
\hline 06 & Rashtriya Madhyamik Shiksha Abhiyan (RMSA) \\
\hline 07 & $\begin{array}{l}\text { Scheme for setting up of } 6000 \text { Model Schools at Block level as Benchmark of } \\
\text { Excellence }\end{array}$ \\
\hline 08 & $\begin{array}{l}\text { Scheme for construction and running of Girl }{ }^{\text {ee }} \text { s Hostel for Secondary and Higher } \\
\text { Secondary Schools }\end{array}$ \\
\hline 09 & Scheme of Vocationalisation of Secondary Education at +2 level \\
\hline 10 & Scheme of ICT@School \\
\hline 11 & Inclusive Education for the Disabled at Secondary School (IEDSS) \\
\hline 12 & Quality Improvement in School \\
\hline 13 & Strengthening of Teachers ${ }^{\text {ee }}$ Training Institutions \\
\hline 14 & Adult Education and Skill Development Scheme \\
\hline 15 & Scheme for Providing a Quality Education in Madarsas (SPQEM) \\
\hline 16 & National Means cum Merit Scholarship Scheme \\
\hline 17 & Scheme for Infrastructure Development in Minority Institutions (IDMI) \\
\hline 18 & National Scheme for Incentive to the Girl Child for Secondary Education \\
\hline 19 & Appointment of Language Teachers \\
\hline 20 & Setting up of New Polytechnics and Strengthening of Existing Polytechnics \\
\hline 21 & Pre-matric Scholarship Scheme \\
\hline 22 & Eklavya Model Residential School (EMRS) \\
\hline
\end{tabular}

Source: Parliament library and reference, research, documentation and information service (LARRDIS) members' reference note. No. 17/rn/ref./ august/2013

Educationists all over the world have come up with number of measures which have proven effective in reducing the dropout problem among students and extracurricular activities is one of them. It has been found that, undertaking extracurricular activities at the school level has proved instrumental in addressing the dropout problem in its own way. As has been observed, that children find it always interesting to indulge in sports and games, which attract them to schools. Besides, by playing games, these children indirectly tone up their bodies and improve their fitness level and develop health conscience. Mahoney \& Cairns (1997) studied 392 subjects, which included 206 girls and 186 boys and observed that dropout rate among high risk students was lower for those who had earlier participated in extracurricular activities than those who did not.

Under Right of Children to Free and Compulsory Education (RTE) Act, 2009 Govt., of India has also created constitutional provisions for compulsory and free education to children in the age group of 6-14 years. The campaign is run all across the country under Sarva Shikhsha Abhiyan. The act has casted obligation on respective state governments and local bodies to ensure admission, attendance and completion of elementary education by all children in the aforementioned age group. 


\section{CONCLUSION}

India is one of the fastest growing economies of the world, which is also being looked at by other nation countries, which can meet out their future human resource demands. And the irony is, the population, which social thinkers till recent past used to dub as a curse in the path of India progress and development, have now started believing that the India's human resource is its real asset, which will play a key part in the growth and development of the country, indeed a blessing in disguise. And the harsh truth is, to meet out the global human resource demand in the coming years, India's education sector has to be robust and strong and in the absence of it, the country cannot produce highly trained and skilled human resource.

There is no denial of the fact, that children are enrolled in schools, but gradually dropout at different stages of their study. As revealed in the study, that on average nearly $58.80 \%$ students' dropout by the time they reach upper primary level and $79.95 \%$ by secondary level each year. There is greater need, that govt should put more emphasis on the secondary education and should try to extend all such benefits along with some additional measures to decrease this dropout percentage. The more we will be able to retain children in schools up to secondary or senior secondary level, better are their chances to undertake higher education, which in turn will prove prudent towards the growth \& development of country and in moving a step forward to have an ideal, utopian and egalitarian society.

Govt and its agencies should work out on some additional soaps and incentives towards the promotion of enrolment and demotion of dropout in general and for girl child in particular. This is will reaffirm our faith, that educating a girl is a step forward towards educating a whole family and is no more a burden.

\section{References}

[1] Battin-Pearson, S., Newcomb, M. D., Abbott, R. D., Hill, K. G., Catalano, R. F., \& Hawkins, J. D. (2000). Predictors of early high school dropout: A test of five theories. Journal of educational psychology, 92(3), 568

[2] Cairns, R. B., Cairns, B. D., \& Neckerman, H. J. (1989). Early school dropout: Configurations and determinants. Child development, 1437-1452.

[3] Canada Manpower and Immigration (1990). Projet national d'incitationa la poursuite des etudes [A national project to encourage persistence in school]. Ottawa: Government of Canada

[4] Department of school education and literacy, Ministry of Human Resource and Development, Govt., of India (n.d). Retrieved on October 02, 2014 from http://mhrd.gov.in/rte

[5] Drèze, J., \& Kingdon, G. G. (2001). School participation in rural India. Review of Development Economics, 5(1), 1-24.

[6] Fetler, M. (1989). School dropout rates, academic performance, size, and poverty: Correlates of educational reform. Educational Evaluation and Policy Analysis, 11(2), 109-116.

[7] Global Education Digest (2012). UNESCO Institute of Statistics, retrieved on October 08, 2014 from http://www.uis.unesco.org/Education/GED\%20Documents\%20C/GED2012-Complete-Web3.pdf 
[8] Hammack, F.M. (1986). Large school systems, dropout ratios: An analysis of definitions, procedures and findings.

[9] Hymel, S., Comfort, C., Schonert-Reichl, K., \& McDougall, P. (1996). Academic failure and school dropout: The influence of peers.

[10] Joseph, K. M. (2014). Development and Effectiveness of Positive Psycho-educational Intervention Program in Enhancement of Student Engagement, Motivation and Alleviation of Depressive Symptoms of Selected School Dropouts. Indian Journal of Positive Psychology, 5(1), 1-10

[11] Khan, S., \& Pandey, G. (2012). Causal factors of school dropouts (A study of Aligarh district, Uttar Pradesh, India). International Journal of Research in Social Sciences, 2(1), 236-241.

[12] Mahoney, J. L., \& Cairns, R. B. (1997). Do extracurricular activities protect against early school dropout?. Developmental psychology, 33(2), 241.

[13] Mann, B. J. (1986). Can we help dropout? Thinking about the undoable. Teachers College Record, 87, 307-323.

[14] Mondal, P., \& Majumder, A. (2013). The socio-economic problems of the school dropout among the primary level ramnagar area of gaighata block, north 24 parganas, West Bengal. Asian Journal of Research in Social Sciences and Humanities, 3(3), 154163.

[15] Office of the Registrar General and Census Commissioner of India, Ministry of Home Affairs, Govt of India. (n.d). Retrieved on October 02, 2014 from http://www.censusindia.gov.in/2011-provresults/data_files/india/Final_PPT_2011_chapter3.pdf

[16] Pittman, R. B., \& Haughwout, P. (1987). Influence of high school size on dropout rate. Educational Evaluation and Policy Analysis, 9(4), 337-343.

[17] Quebec Ministry of Education. (1991). Prevention de Vabandon scolaire [Prevention of school dropout]. Quebec, Canada: Direction Generale de la Recherche et du D6veloppement.

[18] Rumberger, R. W., \& Larson, K. A. (1998). Student mobility and the increased risk of high school dropout. American Journal of Education, 1-35

[19] Vallerand, R. J., \& Blssonnette, R. (1992). Intrinsic, extrinsic, and amotivational styles as predictors of behavior: A prospective study. Journal of personality, 60(3), 599-620.

[20] Vallerand, R. J., Fortier, M. S., \& Guay, F. (1997). Self-determination and persistence in a real-life setting: toward a motivational model of high school dropout. Journal of Personality and Social psychology, 72(5), 1161. 